Bond University

Research Repository

\title{
Recruit Fitness Standards from a Large Law Enforcement Agency: Between-Class Comparisons, Percentile Rankings, and Implications for Physical Training
}

Lockie, Robert G.; Dawes, Jay; Orr, Rob Marc; Dulla, Joe

Published in:

Journal of Strength and Conditioning Research

DOI:

10.1519/JSC.0000000000003534

Licence:

Other

Link to output in Bond University research repository.

Recommended citation(APA):

Lockie, R. G., Dawes, J., Orr, R. M., \& Dulla, J. (2020). Recruit Fitness Standards from a Large Law

Enforcement Agency: Between-Class Comparisons, Percentile Rankings, and Implications for Physical Training. Journal of Strength and Conditioning Research, 34(4), 934-941. https://doi.org/10.1519/JSC.0000000000003534

\section{General rights}

Copyright and moral rights for the publications made accessible in the public portal are retained by the authors and/or other copyright owners and it is a condition of accessing publications that users recognise and abide by the legal requirements associated with these rights.

For more information, or if you believe that this document breaches copyright, please contact the Bond University research repository coordinator 


\section{Recruit Fitness Standards from a Large Law Enforcement Agency: Between-Class Comparisons, Percentile Rankings, and Implications for Physical Training}

\section{Brief Running Head: Law Enforcement Recruit Fitness Standards}

Robert G. Lockie ${ }^{1}$, J. Jay Dawes ${ }^{2}$, Robin M. Orr ${ }^{3}$, Joseph M. Dulla ${ }^{4}$.

${ }^{1}$ Department of Kinesiology, California State University, Fullerton, Fullerton, CA, USA.

${ }^{2}$ Department of Health and Human Performance, Oklahoma State University, Stillwater, OK, USA.

${ }^{3}$ Tactical Research Unit, Bond University, Robina, Qld, Australia.

${ }^{4}$ Recruit Training Unit, Training Bureau, Los Angeles County Sheriff's Department, Los Angeles, CA, USA.

$\square$ Robert Lockie

California State University, Fullerton

Department of Kinesiology

800 N State College Blvd

Fullerton, CA 92831

USA

Phone (international): $\quad+1$ 657-278-3316

Email: $\quad$ rlockie@fullerton.edu 

Class Comparisons, Percentile Rankings, and Implications for Physical Training. Journal of Strength and Conditioning Research. https://doi.org/10.1519/JSC.0000000000003534

\section{Recruit Fitness Standards from a Large Law Enforcement Agency: Between-Class}

Comparisons, Percentile Rankings, and Implications for Physical Training 


\begin{abstract}
Law enforcement can be a physically demanding profession. Many agencies use a 'one-size-fitsall' academy training approach, which may not be optimal for all recruits. There is also little information that benchmarks fitness of law enforcement recruits. The purpose of this study was to analyze between-academy class differences in fitness, as well as produce normative data for the development of strength and conditioning programs. A retrospective analysis of 908 recruits (761 males, 147 females), comprising 11 classes from one agency, was utilized. Fitness assessment data included: push-ups, sit-ups, and mountain climbers in $120 \mathrm{~s}$; pull-ups; 201-m run; and 2.4-km run. A one-way analysis of variance with a Bonferroni post hoc adjustment revealed that fitness varied significantly between classes. Class 11 completed less sit-ups than six other classes $(p \leq 0.033)$ and were slower in the $201-\mathrm{m}$ and $2.4-\mathrm{km}$ run than five classes $(p \leq 0.005)$. Class 7 completed less push-ups than three classes $(p \leq 0.036)$, and less mountain climbers and were slower in the 201-m run than five classes $(p \leq 0.005)$. Individual recruit analysis and percentile data indicated a wide spread of all assessment results, and the effects upon female recruits. For example, $81 \%$ of females completed $\leq 2$ pull-ups and were in the bottom two percentile bands; $72-76 \%$ of females were in the bottom three bands for push-ups and the 201-m run. Fitness varies from class-to-class, and female recruits will generally be less physically fit. Training staff should ideally implement individualized, ability-based programming where appropriate to train their recruits.
\end{abstract}

Key words: academy training; aerobic capacity; muscular endurance; police; tactical 


\section{INTRODUCTION}

Law enforcement officers (LEOs) can experience unique physical demands while on shift. This may include driving a vehicle at high speeds (12), checking bona fides of civilians (12), pursuing suspects (10), clearing obstacles (20), discharging firearms (37), and where necessary, exerting force to apprehend offenders (37). Within the context of these actions, LEOs must also understand organizational procedures for their agency, in addition to the legal ramifications of all their actions when on-duty. Academy training is used by law enforcement agencies (LEAs) to physically and mentally prepare recruits for the demands of their profession $(7,20,24,39)$. The academy training period, however, can be very challenging for recruits $(19,24)$. A major part of this challenge is the physical training that is administered by LEA staff.

Higher levels of physical fitness (e.g. more push-up, sit-up, and mountain climber repetitions completed in a certain time period; maximal pull-up repetitions; a greater vertical jump; more shuttles completed in the 20-m multistage fitness test; and faster 201-m and 2.4-km [1.5mile] run times) can positively influence job-specific tasks for LEOs $(10,20)$. This is one of the reasons why it physical fitness features heavily during academy training. It has been recommended that recruits arrive at academy in good physical condition $(24,26,36,43)$. This is because recruits with poorer fitness are less likely to meet the physical demands of academy; and, accordingly, these poor-fitness recruits do not graduate to become LEOs. Shusko et al. (43) found that recruits who completed fewer push-ups in $60 \mathrm{~s}$ prior to academy and had a slower $2.4-\mathrm{km}$ run time, were more likely to separate from academy. Poorer aerobic fitness as measured by the $20-\mathrm{m}$ multistage fitness test contributed to poorer performance within an individual physical training session (26), in addition to academy separation in California-based law enforcement recruits (24). Further, several studies have indicated that female and older recruits tend towards poorer performance in 
fitness assessments when compared to males and younger recruits $(5,21,26,27)$. This highlights some of the reasons why LEA staff assess the fitness of their recruits at the start of academy. In addition to benchmarking their class, this information can also be used as a reward system for high performers (20).

However, despite standard recommendations to do so (30), fitness assessment data may not be used to influence the design of the physical training program. Many law enforcement training academies operate via a paramilitary, 'one-size-fits-all' training model $(4,15,24,33,39)$, whereby the expectation is that all recruits should complete the same exercises with the same intensity. Although this is often done with the expectation that all LEOs have the same job tasks when on duty, this approach may not be optimal for performance improvements or injury prevention $(15,39)$. Furthermore, Lockie et al. (24) suggested this training approach could be a contributing factor as to why some recruits may voluntarily separate from academy, especially if they are unable to either tolerate or recover from the imposed stress. LEA staff may be more inclined to better periodize their physical training programs if there were established standards for high- and low-performing recruits. Although the periodization of training programs is an expected outcome in the strength and conditioning community, it is not a common outcome in the physical training of law enforcement recruits $(4,15,24,33,39)$. While percentile ranking for a range of fitness measures (vertical jump, push-up and sit up repetitions in $60 \mathrm{~s}$, isometric leg/back strength and grip strength, and the 20 -m multistage fitness test) have been provided for incumbent state patrol officers (11), they have not been presented for law enforcement recruits at the start of academy.

In general, a LEA's human resources department controls the intake of recruits to certain training academy classes. As all agencies have standard expectations for admission to a training academy (e.g. fitness tests, background checks, psychological evaluations) $(1,6)$, this may result 
in limited overall fitness differences between classes (23). If this was the case, this could encourage LEA staff to adopt similar training models across multiple classes, even if this may not be optimal $(15,39)$. In an analysis of three law enforcement academy classes, Lockie et al. (23) found there were no significant differences across the classes in push-ups, sit-ups, and arm ergometer revolutions completed in $60 \mathrm{~s}$, or 75-yard pursuit and 2.4-km run time. Lockie et al. (22) found similar results when analyzing three custody assistant academy classes. However, in two separate studies, Lockie et al. $(22,23)$ documented a wide range of fitness assessment results in their data. As a result, and in line with other authors $(4,24,33)$, recommendations have been made to tailor training to the abilities of individual recruits where appropriate to optimize improvements in fitness $(22,23)$. What would assist with this process is further analysis of any fitness variation between academy classes, and clear profiles of higher and lower performance in common fitness assessments for law enforcement recruits. Dawes et al. (11) noted the importance of doing this, as this information could be used to design strength and conditioning programs to improve, or maintain, fitness of law enforcement populations.

Therefore, the current study analyzed the fitness characteristics of 11 academy classes from one LEA. The LEA in this study is the largest sheriff's department in the world, employing 18,000 personnel, with a patrol area of approximately $10600 \mathrm{~km}^{2}$ (29). Accordingly, the data presented provides an effective representation of law enforcement recruits in the USA. Furthermore, the provision of empirical evidence regarding law enforcement populations is essential, as this provides tangible support for staff who wish to implement any changes to the training of recruits. The fitness assessment battery was referred to as the PT500, and has been presented in the literature (20). As previous research has shown a high variability of fitness assessment results in law enforcement recruit classes $(22,23)$, with a greater tendency for female recruits to be in the lower 
percentiles $(11,21,25)$, the hypothesis in this study was modelled to reflect an a priori approach (44). Accordingly, it was hypothesized that there would be significant differences between the academy classes in the fitness variables. Specifically, certain classes would perform more pushups, sit-ups, mountain climbers, and pull-ups, and would be faster in the 201-m and 2.4-km runs compared to other classes. As the LEA human resources department controlled the intake of recruits to certain classes, and this was dependent on numerous other factors not connected to fitness (e.g. time taken to complete background checks and psychological evaluations) $(1,6)$, the hypothesis did not relate to specific classes. Nonetheless, it was hypothesized that certain classes would outperform others in the fitness assessments.

\section{METHODS}

\section{Experimental Approach to the Problem}

A retrospective analysis of pre-existing data for recruits belonging to 11 classes from one LEA was conducted. The first part of the analysis involved analyzing different training cohorts of recruits commencing training at a LEA. The recruit pool was stratified into these 11 naturally occurring cohorts, and a one-way analysis of variance (ANOVA) was used to compare data. The second part of the analysis involved setting population-specific normative values through the use of percentile rankings of each PT500 fitness assessment (11). The PT500 was comprised of: pushups, sit-ups, and mountain climbers completed in $120 \mathrm{~s}$; maximal number of pull-ups; a 201-m run; and a 2.4-km run. The dependent variables for this study were: age, height, and body mass; push-up repetitions; sit-up repetitions; mountain climber repetitions; pull-up repetitions; 201-m run time; and 2.4-km run time. 


\section{Subjects}

Data were collected by the staff of one LEA in the USA and was released with consent from that organization to the investigators. A sample of convenience comprised of 908 recruits (age: 27.16 \pm 5.70 years; height: $1.74 \pm 0.09 \mathrm{~m}$; body mass: $80.03 \pm 12.93 \mathrm{~kg}$ ) was analyzed, which consisted of 761 males (age: $27.19 \pm 5.86$ years; height: $1.76 \pm 0.07 \mathrm{~m}$; body mass: $83.01 \pm 11.39 \mathrm{~kg}$ ) and 147 females (age: $26.97 \pm 4.78$ years; height: $1.63 \pm 0.07 \mathrm{~m}$; body mass: $64.55 \pm 8.73 \mathrm{~kg}$ ). The characteristics of the subjects in this study, in addition to the ratio between males and females, was typical of law enforcement populations $(5,20,21,23,28)$. No control was placed on strength and conditioning practices or dietary interventions of individual recruits during the period prior to academy $(21,24,28)$. Based on the archival nature of this analysis, the institutional ethics committee approved the use of pre-existing data (HSR-17-18-370). Recruits were required to complete the fitness assessments as part of their physical training within academy for this agency. Regardless, the study still conformed to the recommendations of the Declaration of Helsinki.

\section{Procedures}

The data in this study were collected by staff working for one LEA. The staff were all trained by a certified Tactical Strength and Conditioning Facilitator (TSAC-F) who verified the proficiency of the staff members. For Classes 2-10, each recruit's age, height, and body mass were recorded in the week preceding the start of the 22-week academy training period. Height was measured barefoot using a portable stadiometer (Seca, Hamburg, Germany), while body mass was recorded by electronic digital scales (Health o Meter, Neosho, Missouri). For Classes 1 and 11, age, height, and body mass data were recorded by training staff during academy and were provided to the researchers, which is common practice within law enforcement research $(10,11,25)$. The PT500 
was completed in the first week of academy, and depending on the class schedule, typically between 0500-0900 (5:00am-9:00am). The weather conditions for testing were representative of the climate of southern California during a calendar year. Although conducting testing outdoors is not ideal, there was no indoor testing facility available for this LEA and these procedures were typical of staff from the LEA (i.e. during the hiring process, for recruits during academy, and for incumbents during skill refresher programs).

\section{Fitness Assessment Battery - PT500}

The PT500 was used by staff at this LEA to award fitness pins for high-performing recruits (20), and as stated, was comprised of six assessments. These were: maximal push-ups, sit-ups, and mountain climbers completed in $120 \mathrm{~s}$; maximal number of pull-ups; 201-m run; and 2.4-km run. The PT500 was an established standard of fitness assessment used by this LEA for a number of years (20). Recruits performed the PT500 in their typical physical training attire. The push-ups, sit-ups, and mountain climbers were conducted outdoors on a concrete surface, and each test was completed with a partner who counted the number of repetitions before the partners alternated. Pull-ups were completed on an outdoor bar. The 201-m and 2.4-km run was performed on a dirt athletics track at the LEA's facility. The recruits completed the runs in their platoons, which generally consisted of 10-15 per group. Although the PT500 assessments have been described by Lockie et al. (20), the procedures for each will be presented here.

Push-ups: Upper-body muscular endurance was assessed via a maximal push-up test where recruits completed as many repetitions as they could in $120 \mathrm{~s}$. The technique used for this assessment is typical for law enforcement populations $(5,7-10,25,27,38)$. Recruits started in the 
standard 'up' position, with the body taut and straight, the hands positioned shoulder-width apart, and the fingers pointed forwards. Staff at the LEA utilized a standard water bottle to determine the bottom position of the push-up, which was positioned underneath the recruit's chest (23). On the start command, a staff member began the stopwatch, and recruits flexed their elbows, lowered themselves until their chests contacted the water bottle, before extending their elbows to return to the start position. The recruits performed as many push-ups as possible using this technique.

Sit-ups: Muscular endurance of the abdominal muscles was assessed via the sit-up test, where recruits completed as many repetitions as possible in $120 \mathrm{~s}$. The technique used for the sit-up assessment was typical for law enforcement populations $(5,7-10,25,27,38)$. The recruits laid on their backs with their knees flexed to $90^{\circ}$, heels flat on the ground, and hands cupped behind their ears. The feet were held to the ground by a partner during the test. On the start command, recruits raised their shoulders from the ground while keeping their hands cupped at their ears and touched their elbows to their knees. The recruit then descended back down until their shoulder blades contacted the ground and completed as many repetitions as possible.

Mountain climbers: Mountain climbers involve isometric work for the trunk musculature and dynamic hip and knee flexion and extension (20,32), and was another muscular endurance assessment. Recruits started in the standard 'up' position for the push-up and maintained the position with the arms extended throughout the test. The back was to remain in neutral alignment, and recruits alternated flexing the hip and knee for each leg in movements that brought the knee close to the chest and the foot underneath the body within each repetition. The recruits completed as many repetitions as possible with this technique in $120 \mathrm{~s}$. 
Pull-ups: The pull-up test provided a measure of upper-body pulling strength (42), and has been used to measure this quality in law enforcement recruits $(20,27)$. Recruits started by hanging onto the bar in a vertical position with their hands shoulder-width apart using a pronated grip. The recruit then pulled themselves up, while maintaining a vertical body alignment until their chin was over the bar to complete one repetition. The recruit then descended to a position where the arms were fully extended and continued to complete repetitions until they could no longer get their chin over the bar.

201-m run: The 201-m run provided a measure of anaerobic capacity (31) and has been utilized in law enforcement recruits $(20,27)$. The $201-\mathrm{m}$ distance was marked on a dirt athletics track. The recruits were to run the distance as quickly as possible. Time for each recruit was recorded to the nearest $0.1 \mathrm{~s}$ by a handheld stopwatch. Stopwatch timing is standard practice in LEA testing $(7,9,23,25,27,28)$.

2.4-km run: The 2.4-km run provided a measure of aerobic capacity (31) and is a common test used to in law enforcement populations $(5,7,9,23,25,27,38,43)$. The recruits completed six laps, as quickly as possible, around the dirt athletics track at the training facility. The run time was recorded for each recruit on a handheld stopwatch to the nearest $0.1 \mathrm{sec}$. Time was recorded as minutes: seconds (min: s). 


\section{Statistical Analysis}

Statistical analyses were processed using the Statistics Package for Social Sciences (SPSS) Version 25.0 (IBM Corporation, New York, USA), and Microsoft Excel (Microsoft Corporation $^{\mathrm{TM}}$, Redmond, Washington, USA). Descriptive statistics (mean \pm standard deviation [SD]) were calculated for each variable. A one-way ANOVA, with Bonferroni post hoc adjustment for multiple pairwise comparisons, was used to calculate any differences between the classes. This type of analysis was conducted due to the size of the sample, and the robustness of the one-way ANOVA $(13,25)$. The sexes were combined for the class analysis as the agency did not use any corrections for sex when assigning awards based on the PT500. Indeed, previous research has combined data for the sexes in law enforcement research $(5,20,21,23,25,28)$. The alpha was set at $p<0.05$. Microsoft Excel was used to calculate the percentile ranks for each fitness assessment in bands of 10 percentile ranks. The number of male and female recruits within each percentile rank was noted.

\section{RESULTS}

The age, height, and body mass data for each class is shown in Table 1 . There were no significant differences in age or body mass between the classes. However, Class 7 was significantly shorter than Classes $3(p=0.001), 8(p=0.001)$, and $11(p=0.040)$. Class 10 was shorter than Classes 3 $(p=0.034)$ and $8(p=0.021)$. There were no other between-class differences in height.

\section{***INSERT TABLE 1 ABOUT HERE***}


Data for the fitness assessments is shown in Table 2. Class 7 completed significantly fewer push-ups than Classes 2,6 , and $9(p \leq 0.036)$. Classes $4(p=0.013)$ and $8(p=0.047)$ completed fewer push-ups than Class 6. Class 11 completed significantly fewer sit-ups than Classes 3, 4, 5, 6,8 , and $9(p \leq 0.033)$. Classes $3,4,6,7,8$, and 11 performed significantly fewer mountain climbers than Classes $1,2,5,9$, and $10(p \leq 0.043)$. Class 10 completed fewer mountain climbers than Classes 1,5 , and $9(p \leq 0.010)$. Regarding pull-ups, Class 2 completed fewer repetitions compared to Class $4(p=0.049)$. In the 201-m run, Classes 6,7 , and 11 were significantly slower than Classes $2,3,5,8$, and $9(p \leq 0.046)$. Class 10 was slower than Class $9(p=0.001)$. Lastly, in the 2.4-km run, Classes $1,3,4,6$, and 10 were significantly slower than Classes 5 and 9 ( $p \leq$ 0.010). Class 8 was slower than Class $9(p=0.009)$. Class 11 was slower than Classes $1,2,5,8$, and $9(p \leq 0.002)$.

\section{***INSERT TABLE 2 ABOUT HERE***}

The percentile normative ranking data for all the fitness assessments is shown in Tables 38. Where possible, data were presented in bands of 10 percentile ranks. However, for push-ups (Table 3), 362 recruits performed 50 push-ups, which affected the spread of recruits across the percentile bands. The push-up assessment had a low of 0 repetitions, and a high of 113 repetitions. Sit-up data is displayed in Table 4, and this assessment had a low of 13 repetitions, and a high of 110 repetitions. Regarding mountain climbers (Table 5), the great majority of subjects performed 60 repetitions or less. Accordingly, those recruits that completed more than 61 repetitions covered the top four percentile bands. Mountain climbers had a low of 5 repetitions, and a high of 89 repetitions. Pull-ups had a low of 0 repetitions, and a high of 33 repetitions, and the percentile 
ranking data is shown in Table 6. The 201-m run normative data can be seen in Table 7; the slowest time was $63 \mathrm{~s}$, while the fastest time was $20 \mathrm{~s}$. For the 2.4-km run (Table 8), the slowest time was 20:10 min: s; the fastest time was 7:50 min: s.

\section{***INSERT TABLES 3-8 ABOUT HERE***}

What is noticeable across all the fitness assessments is the number of female recruits towards the bottom of the percentile ranks. For example, more than $80 \%$ of all female recruits (119/147) completed 2 pull-up repetitions or less (Table 6). Concerning push-ups, 76\% (111/147) of females were in the bottom three percentile bands (compared to $21 \%$, or $159 / 761$, of male recruits) (Table 3). Additionally, 72\% (106/147) and 58\% (85/147) of the female recruits were in the bottom three percentile bands for the 201-m run (Table 7) and 2.4-km run (Table 8), respectively (compared to $17 \%$ and $24 \%$ of the male recruits).

\section{DISCUSSION}

This study analyzed the physical fitness characteristics of 11 academy classes to determine whether there were differences in fitness between the classes as measured by the PT500, and to define percentile ranks for the assessments in the PT500. Although the data was specific to one agency, this LEA is the largest sheriff's department in the world (29), and the data presented was typical of that shown in previous law enforcement research $(5,20,21,23,28)$. This provides a good range of fitness assessment data that could be extrapolated to other agencies. The results from this study indicated that there were significant differences in body height and certain fitness tests when comparing mean values between the classes. These results contrasted those from Lockie et al. (23). 
However, Lockie et al. (23) only analyzed three classes (as opposed to the 11 investigated in this study). Further to this, Lockie et al. (23) did note the wide ranges of results across the fitness assessments from their study (push-up repetitions, sit-up repetitions, and arm ergometer revolutions in $60 \mathrm{~s}, 75$-yard pursuit run, and $2.4 \mathrm{~km}$ run). This was confirmed by the data in this study. The results from this study have important implications for how LEA staff should approach the physical training of recruits.

Performance in maximal running assessments has been linked to better performance in occupational tests for law enforcement recruits (20) and officers (10). As hypothesized, numerous classes produced significantly different mean times for the two running tests from this study; the 201-m and 2.4-km runs. Although these running tests should emphasize different physiological traits (i.e. the $201-\mathrm{m}$ run places greater demands on anaerobic capacity, while the $2.4-\mathrm{km}$ is an aerobic capacity test) (31), there would be crossover between the tests. Indeed, several studies have indicated significant relationships between shorter duration sprint tests and aerobic running tests in law enforcement populations $(5,20,34)$. This highlights why certain classes (Classes $6,7,10$, and 11) tended to perform poorer in both tests. Additionally, this data juxtaposed that of Lockie et al. (23), who found no significant differences in the 75-yard pursuit run and 2.4-km run in law enforcement recruits. However, Lockie et al. (23) analyzed data that was collected during the hiring process for the recruits. The testing conditions during the first week of academy would be very different to that from testing during the hiring process. This LEA adopted a paramilitary model for academy training $(15,18)$, which means training staff impart great psychological stress on recruits $(3,19)$. This stress places a palpable physiological response (e.g. increased heart rate) (19), which could then impact performance during physical activity (26). This could have contributed to some of the variation of running test performance. Nonetheless, and in support of 
research on custody assistant recruits (22), there was an increased variability in response times for the $201-\mathrm{m}$ run and $2.4-\mathrm{km}$ in the law enforcement recruits from this study. This adds further evidence to the notion that a one-size-fits-all training model should not be utilized for training law enforcement recruits $(15,39)$, even within the same LEA using the same training program, and, as such, a more individual or ability-based focus should be implemented where possible $(4,22-24,33)$.

There were also variations across classes in the number of push-up and mountain climber repetitions completed, and a wide variation between repetitions completed for individual recruits. Push-ups are a staple fitness assessment in law enforcement populations $(5,7-10,23,25,27,38)$, and performance in this task has been related to the ability to graduate academy (43) and tasks such as barrier clearance and obstacle course performance (10,20). Lockie et al. (20) also found significant correlations (albeit small) between mountain climbers and a six-foot solid wall climb $(r=-0.127)$ and 500-yard run $(r=-0.264)$ in law enforcement recruits, providing some importance for the physical qualities stressed by this exercise. These results further emphasize the need for individualized or ability-based training for law enforcement recruits, especially if muscular endurance (as measured by push-ups and mountain climbers) is viewed as important by LEA staff.

There were fewer differences between the classes in the pull-up and sit-up assessments which was somewhat contrary to the studies' hypothesis, although Classes 2 and 11 did appear to perform more poorly in those tasks, respectively. Pull-ups can provide a measure of upper-body pulling and relative strength (42), and pull-ups have been correlated to performance of six-foot chain link fence $(r=-0.315)$ and solid wall climbs $(r=-0.309)$ in law enforcement recruits $(20)$. As for push-ups, sit-ups are a staple assessment in law enforcement populations (5,710,23,25,27,38). This is the case despite literature stating that there are limitations within this exercise, in that it can place undue stress on the lower back (2). Nonetheless, sit-ups can provide 
a measure of abdominal muscle endurance (45), and along with pull-ups, the data from this study indicated minimal significant between-class differences in these assessments. However, in support of previous research $(22,23)$, there was an increased variability in the number of repetitions completed between recruits in both the pull-ups and sit-ups. As will be discussed, this was reinforced by the percentile ranking data for all fitness assessments.

Similar to percentile charts produced by Dawes et al. (11) for incumbent state patrol officers, percentile rankings for the PT500 were produced in this study to provide an interim profile of law enforcement recruits unique to this population, and to inform future research and training program design. Interestingly, the percentile ranks for push-ups and sit-ups in this study tended to be superior to those from Dawes et al. (11). This highlights the declines in fitness that tend to occur on the job (38), and the need for different percentile rankings for recruits versus incumbents. For recruits, training is the job, whereas for qualified LEOs the police work is the job. In support of previous research $(22,23)$, the percentile rank data indicated great variation in the individual performances of recruits in all PT500 assessments. This provides further support to utilizing individualized, ability-based programming for law enforcement recruits $(4,22-24,33)$. What is also notable are the number of females in the lower percentile ranks for all assessments. Although this was not unexpected, given that previous research has demonstrated that female recruits tend to perform poorer on fitness assessments compared to males $(5,21,27)$, these data still have important implications for training staff. LEA staff should recognize that their female recruits may be working at a relatively higher intensity for the same exercise when compared to male recruits, which could increase their risk of injury (16). Accordingly, fitness differences, rather than sex differences, could explain the higher rates of injuries in female trainees $(17,41)$. Inappropriate application of training load and intensity, especially that beyond the current capacities of female 
recruits, could also influence the retention of females $(24,26)$. Female recruits in particular could stand to benefit from ability-based training during law enforcement academy training.

McGuigan (30) recommended using fitness test data to inform future programming for training, and this is a typical approach for athletes. However, although fitness assessment data can be used to reward recruits for their efforts during academy (20), it is generally not utilized in the design of the physical training program $(4,24,33)$. There are several reasons for this. As demonstrated in this study, academy class sizes for this LEA tend to be very large, which can make individualized programming difficult. There can also be limitations with equipment and space for physical training (33). Furthermore, the administering body for California law enforcement officers (Peace Officer Standards and Training) only mandates the minimum number of physical training sessions required in an academy (36 sessions in a 6-month academy), and provides some general recommendations as to what this should entail (40). If an agency adheres to the minimum standard, this would result in an average of only $1 \frac{1}{2}$ physical training sessions per week. This is well below general recommendations for enhancing aerobic ( $\geq 5$ sessions per week) and musculoskeletal ( $\geq 3$ sessions per week) fitness for apparently healthy adults (14). The potential low number of physical training sessions per week during academy could have impacted the results seen in this study. Furthermore, there are no mandates as to how the physical training program should be periodized for Californian law enforcement recruits, nor how recruits of different fitness levels should be trained (40). Appropriate programming based on sound scientific principles can enhance the physical fitness and reduce injury risk in law enforcement recruits during academy (15). Example ability-based strength (33) and aerobic conditioning (4) programs for law enforcement recruits have also been presented in the literature. Further to this, it would be beneficial for LEAs to utilize trained professionals (e.g. Certified Strength and Conditioning 
Specialists [CSCS] and TSAC-F) to design physical training programs specific to their recruits.

This is especially important given the results of this study, where the data indicated variations in fitness across between academy classes and individual recruits.

There are several study limitations that should be noted. This study only incorporated one agency. However, given the size of the agency (29), this ensured a range of recruits with different fitness levels, which should provide a strong representation of the characteristics of law enforcement recruits in the USA. Testing and environmental conditions may have varied across classes, although this limitation is almost unavoidable given the need for this agency to run academy classes year-round. No maximal strength or power tests were incorporated in the PT500. Several studies have noted the importance of further analysis on the maximal strength and power capacities of law enforcement recruits $(20,35)$. Greater analysis of the maximal strength of law enforcement recruits is required, in addition to the generation of normative data. Future research should also investigate whether the use of normative data such as that provided in this research can lead to effective programming of physical training. There should be greater analysis as to the generalizability of the current data to with respect to individualized training for older individuals. This is essential, given that older recruits tend to perform poorer in a range of fitness assessments $(5,21,26,27)$, which could affect their ability to graduate academy (24). Lastly, although the information presented in this study may be common anecdotal knowledge amongst LEA staff, it is important to provide empirical data to support decisions about physical training.

\section{PRACTICAL APPLICATIONS}

The results from this study demonstrated that the physical fitness of law enforcement recruits, as measured by an agency-specific battery called the PT500, can vary across different academy 
classes. In particular, performance in push-ups, mountain climbers, the 201-m run, and the 2.4-km were different across classes. Normative percentile ranking data was also provided from this study, and this indicated great variation between individual recruits. What was notable was the number of females towards the bottom of the percentile bands for all assessments. Considering the results of this study, it is recommended that where appropriate, LEA training staff use fitness assessment data to direct their physical training program. Fitness assessment data can be used to illustrate strengths and weaknesses of recruits, such that specific qualities of fitness (i.e. anaerobic and aerobic capacity) that could assist with future job performance can be improved. This is vitally important, as previously noted; and, although this is expected to be common practice within exercise programming, it does not often happen within physical training in law enforcement academies $(4,15,24,33,39)$. To optimize this process, it is further recommended that LEA hire and utilize CSCS and TSAC-F to design physical training programs for law enforcement recruits. This could lead to better performance outcomes for training, as well as potentially reducing the risk of injury by implementing specific, ability-based strength and conditioning training programs for law enforcement recruits.

\section{ACKNOWLEDGEMENTS}

This research project received no external financial assistance. None of the authors have any conflict of interest. The authors would like to thank the training instructors for facilitating this research, and the California State University, Fullerton tactical research team for collating the data. 


\section{REFERENCES}

1. Arvey, RD, Landon, TE, Nutting, SM, and Maxwell, SE. Development of physical ability tests for police officers: a construct validation approach. J Appl Psychol 77: 996-1009, 1992.

2. Axler, CT and McGill, SM. Low back loads over a variety of abdominal exercises: searching for the safest abdominal challenge. Med Sci Sports Exerc 29: 804-811, 1997.

3. Berg, BL. First day at the police academy: Stress-Reaction-Training as a screening-out technique. J Contemp Crim Justice 6: 89-105, 1990.

4. Cesario, K, Moreno, M, Bloodgood, A, and Lockie, R. A sample ability-based conditioning session for law enforcement and correctional recruits. TSAC Report 52: 6-11, 2019.

5. Cesario, KA, Dulla, JM, Moreno, MR, Bloodgood, AM, Dawes, JJ, and Lockie, RG. Relationships between assessments in a physical ability test for law enforcement: Is there redundancy in certain assessments? Int J Exerc Sci 11: 1063-1073, 2018.

6. Cochrane, RE, Tett, RP, and Vandecreek, L. Psychological testing and the selection of police officers: A national survey. Crim Justice Behav 30: 511-537, 2003.

7. Cocke, C, Dawes, J, and Orr, RM. The use of 2 conditioning programs and the fitness characteristics of police academy cadets. J Athl Train 51: 887-896, 2016.

8. Crawley, AA, Sherman, RA, Crawley, WR, and Cosio-Lima, LM. Physical fitness of police academy cadets: Baseline characteristics and changes during a 16-week academy. $J$ Strength Cond Res 30: 1416-1424, 2016.

9. Dawes, JJ, Orr, RM, Siekaniec, CL, Vanderwoude, AA, and Pope, R. Associations between anthropometric characteristics and physical performance in male law enforcement officers: 
A retrospective cohort study. Ann Occup Environ Med 28: doi:10.1186/s40557-016-0112-

$5,2016$.

10. Dawes, JJ, Lindsay, K, Bero, J, Elder, C, Kornhauser, C, and Holmes, R. Physical fitness characteristics of high vs. low performers on an occupationally specific physical agility test for patrol officers. J Strength Cond Res 31: 2808-2815, 2017.

11. Dawes, JJ, Orr, RM, Flores, RR, Lockie, RG, Kornhauser, C, and Holmes, R. A physical fitness profile of state highway patrol officers by gender and age. Ann Occup Environ Med 29: doi:10.1186/s40557-017-0173-0, 2017.

12. Decker, A, Orr, RM, Pope, R, and Hinton, B. Physiological demands of law enforcement occupational tasks in Australian police officers. J Aust Strength Cond 24: 78-79, 2016.

13. Gamage, J and Weerahandi, S. Size performance of some tests in one-way ANOVA. Commun Stat Simul Comput 27: 625-640, 1998.

14. Garber, CE, Blissmer, B, Deschenes, MR, Franklin, BA, Lamonte, MJ, Lee, IM, Nieman, DC, and Swain, DP. American College of Sports Medicine position stand. Quantity and quality of exercise for developing and maintaining cardiorespiratory, musculoskeletal, and neuromotor fitness in apparently healthy adults: guidance for prescribing exercise. $\mathrm{Med} S \mathrm{Sc}$ Sports Exerc 43: 1334-59, 2011.

15. Holmes, RJ and Kornhauser, CL, Building Injury Free Tactical Athletes: A Repeatable Model for Police Academy Recruit Training, in TSAC Annual Training: Norfolk, VA, 2018.

16. Jones, BH, Bovee, MW, Harris, JM, and Cowan, DN. Intrinsic risk factors for exerciserelated injuries among male and female army trainees. Am J Sports Med 21: 705-710, 1993. 
17. Knapik, JJ, Grier, T, Spiess, A, Swedler, DI, Hauret, KG, Graham, B, Yoder, J, and Jones, $\mathrm{BH}$. Injury rates and injury risk factors among Federal Bureau of Investigation new agent trainees. BMC Public Health 11: 920, 2011.

18. Kraska, PB. Militarization and policing - Its relevance to 21 st century police. Policing: $A$ Journal of Policy and Practice 1: 501-513, 2007.

19. Lockie, RG, Cesario, KA, Bloodgood, AM, and Moreno, MR. Heart rate response to psychological stress: Importance of stress education for law enforcement recruits. TSAC Report 51: 4-7, 2018.

20. Lockie, RG, Dawes, JJ, Balfany, K, Gonzales, CE, Beitzel, MM, Dulla, JM, and Orr, RM. Physical fitness characteristics that relate to Work Sample Test Battery performance in law enforcement recruits. Int J Environ Res Public Health 15: doi:10.3390/ijerph15112477, 2018.

21. Lockie, RG, Dawes, JJ, Orr, RM, Stierli, M, Dulla, JM, and Orjalo, AJ. An analysis of the effects of sex and age on upper- and lower-body power for law enforcement agency recruits prior to academy training. J Strength Cond Res 32: 1968-1974, 2018.

22. Lockie, RG, Fazilat, B, Dulla, JM, Stierli, M, Orr, RM, Dawes, JJ, and Pakdamanian, K. A retrospective and comparative analysis of the physical fitness of custody assistant classes prior to academy training. Sport Exerc Med Open J 4: 44-51, 2018.

23. Lockie, RG, Stierli, M, Dawes, JJ, Cesario, KA, Moreno, MR, Bloodgood, AM, Orr, RM, and Dulla, JM. Are there similarities in physical fitness characteristics of successful candidates attending law enforcement training regardless of training cohort? J Trainol 7: $5-9,2018$. 
24. Lockie, RG, Balfany, K, Bloodgood, AM, Moreno, MR, Cesario, KA, Dulla, JM, Dawes, JJ, and Orr, RM. The influence of physical fitness on reasons for academy separation in law enforcement recruits. Int $J$ Environ Res Public Health 16: doi.org/10.3390/ijerph16030372, 2019.

25. Lockie, RG, Dawes, JJ, Kornhauser, CL, and Holmes, RJ. Cross-sectional and retrospective cohort analysis of the effects of age on flexibility, strength endurance, lowerbody power, and aerobic fitness in law enforcement officers. J Strength Cond Res 33: 451$458,2019$.

26. Lockie, RG, Moreno, MR, Cesario, KA, McGuire, MB, Dawes, JJ, Orr, RM, and Dulla, JM. The effects of aerobic fitness on day one physical training session completion in law enforcement recruits. J Trainol 8: 1-4, 2019.

27. Lockie, RG, Orr, RM, Stierli, M, Cesario, KA, Moreno, MR, Bloodgood, AM, Dulla, JM, and Dawes, JJ. The physical characteristics by sex and age for custody assistants from a law enforcement agency. J Strength Cond Res 33: 2223-2232, 2019.

28. Lockie, RG, Ruvalcaba, TR, Stierli, M, Dulla, JM, Dawes, JJ, and Orr, RM. Waist circumference and waist-to-hip ratio in law enforcement agency recruits: Relationship to performance in physical fitness tests. $J$ Strength Cond Res: doi:10.1519/jsc.0000000000002825, in press.

29. Los Angeles County Sheriff's Department. About Us, 2017. Available at: http://www.lasd.org/about_us.html. Accessed May 31, 2019.

30. McGuigan, MR. Principles of Test Selection and Administration, In Essentials of Strength Training and Conditioning. G.G. Haff and N.T. Triplett, eds. Human Kinetics: Champaign, IL, 2015. pp. 249-258. 
31. McKardle, WD, Katch, FI, and Katch, VL. Exercise Physiology: Nutrition, Energy, and Human Performance. Vol. 8th. Baltimore, MD: Wolters Kluwer Health, 2015.

32. Mendrin, N, Lynn, SK, Griffith-Merritt, HK, and Noffal, GJ. Progressions of isometric core training. Strength Cond J 38: 50-65, 2016.

33. Moreno, M, Cesario, K, Bloodgood, A, and Lockie, R. Circuit strength training with ability-based modifications for law enforcement recruits. TSAC Report 51: 26-33, 2018.

34. Moreno, MR, Lockie, RG, Kornhauser, CL, Holmes, RJ, and Dawes, JJ. A preliminary analysis of the relationship between the multistage fitness test and 300-m run in law enforcement officers: Implications for fitness assessment. Int J Exerc Sci 11: 730-738, 2018.

35. Moreno, MR, Dulla, JM, Dawes, JJ, Orr, RM, Cesario, KA, and Lockie, RG. Lower-body power and its relationship with body drag velocity in law enforcement recruits. Int J Exerc Sci 12: 847-858, 2019.

36. Orr, R, Pope, R, Peterson, S, Hinton, B, and Stierli, M. Leg power as an indicator of risk of injury or illness in police recruits. Int $J$ Environ Res Public Health 13: doi:10.3390/ijerph13020237, 2016.

37. Orr, R, Pope, R, Stierli, M, and Hinton, B. Grip strength and its relationship to police recruit task performance and injury risk: A retrospective cohort study. Int J Environ Res Public Health 14: doi:10.3390/ijerph14080941, 2017.

38. Orr, R, Dawes, JJ, Pope, R, and Terry, J. Assessing differences in anthropometric and fitness characteristics between police academy cadets and incumbent officers. J Strength Cond Res: doi:10.1519/JSC.0000000000002328, in press. 
39. Orr, RM, Ford, K, and Stierli, M. Implementation of an ability-based training program in police force recruits. J Strength Cond Res 30: 2781-2787, 2016.

40. Peace Officer Standards and Training. Training and Testing: Specifications for Learning Domain \#32 Lifetime Fitness, 2013. Available from: https://post.ca.gov/post_docs/training/trainingspecs/LD32.doc. Accessed July 18, 2019.

41. Piantanida, NA, Knapik, JJ, Brannen, S, and O'Connor, F. Injuries during Marine Corps officer basic training. Mil Med 165: 515-520, 2000.

42. Sanchez-Moreno, M, Pareja-Blanco, F, Diaz-Cueli, D, and González-Badillo, JJ. Determinant factors of pull-up performance in trained athletes. J Sports Med Phys Fitness 56: 825-833, 2016.

43. Shusko, M, Benedetti, L, Korre, M, Eshleman, EJ, Farioli, A, Christophi, CA, and Kales, SN. Recruit fitness as a predictor of police academy graduation. Occup Med 67: 555-561, 2017.

44. Szucs, D and Ioannidis, JPA. When null hypothesis significance testing is unsuitable for research: A reassessment. Front Hum Neurosci 11, 2017.

45. Vaara, JP, Kyrolainen, H, Niemi, J, Ohrankammen, O, Hakkinen, A, Kocay, S, and Hakkinen, K. Associations of maximal strength and muscular endurance test scores with cardiorespiratory fitness and body composition. J Strength Cond Res 26: 2078-2086, 2012. 
Table 1: Age, height, and body mass (mean $\pm \mathrm{SD}$ ) from 11 recruit classes from one LEA.

Significance was set as $p<0.05$.

\begin{tabular}{cccc}
\hline & Age & Height & Body Mass \\
\hline Class $1(\mathrm{n}=90)$ & $26.87 \pm 5.27$ & $1.74 \pm 0.09$ & $79.00 \pm 13.10$ \\
Class $(\mathrm{n}=93)$ & $28.12 \pm 6.12$ & $1.74 \pm 0.08$ & $83.54 \pm 11.99$ \\
Class $3(\mathrm{n}=66)$ & $25.77 \pm 4.06$ & $1.77 \pm 0.08$ & $80.00 \pm 11.47$ \\
Class $4(\mathrm{n}=79)$ & $27.22 \pm 6.20$ & $1.73 \pm 0.10$ & $78.15 \pm 13.31$ \\
Class $5(\mathrm{n}=67)$ & $26.58 \pm 5.66$ & $1.74 \pm 0.08$ & $79.09 \pm 11.49$ \\
Class $6(\mathrm{n}=88)$ & $27.14 \pm 5.63$ & $1.74 \pm 0.09$ & $78.94 \pm 12.41$ \\
Class $7(\mathrm{n}=83)$ & $26.88 \pm 5.05$ & $1.71 \pm 0.09^{\mathrm{a}}$ & $77.56 \pm 13.38$ \\
Class $8(\mathrm{n}=84)$ & $27.92 \pm 6.57$ & $1.77 \pm 0.08$ & $81.00 \pm 14.33$ \\
Class $9(\mathrm{n}=79)$ & $27.04 \pm 5.25$ & $1.73 \pm 0.08$ & $81.65 \pm 13.78$ \\
Class $10(\mathrm{n}=89)$ & $26.92 \pm 6.15$ & $1.72 \pm 0.08^{\mathrm{b}}$ & $79.99 \pm 12.45$ \\
Class $11(\mathrm{n}=88)$ & $27.68 \pm 5.86$ & $1.75 \pm 0.09$ & $80.71 \pm 13.40$ \\
& & & \\
& & &
\end{tabular}

${ }^{a}$ Significantly shorter than Classes 3, 8, and 11.

${ }^{\mathrm{b}}$ Significantly shorter than Classes 3 and 8 . 
Table 2: Fitness assessment data (mean $\pm \mathrm{SD}$ ) from 11 recruit classes from one LEA. Significance was set at $p<0.05$.

\begin{tabular}{|c|c|c|c|c|c|c|}
\hline & $\begin{array}{c}\text { Push-ups } \\
\text { (repetitions) }\end{array}$ & $\begin{array}{c}\text { Sit-ups } \\
\text { (repetitions) }\end{array}$ & $\begin{array}{c}\text { Mountain Climbers } \\
\text { (repetitions) }\end{array}$ & $\begin{array}{c}\text { Pull-ups } \\
\text { (repetitions) }\end{array}$ & $\begin{array}{c}\text { 201-m Run } \\
\text { (s) }\end{array}$ & $\begin{array}{l}\text { 2.4-km Run } \\
\text { (min: s) }\end{array}$ \\
\hline Class $1(n=90)$ & $46.84 \pm 7.20$ & $53.50 \pm 14.47$ & $58.60 \pm 4.87$ & $10.16 \pm 6.60$ & $34.70 \pm 4.34$ & $12: 01 \pm 1: 10^{\mathrm{i}}$ \\
\hline Class $2(n=93)$ & $48.16 \pm 15.09$ & $54.16 \pm 13.69$ & $53.09 \pm 12.06$ & $7.87 \pm 4.90^{\mathrm{f}}$ & $34.06 \pm 3.74$ & $11: 58 \pm 1: 15$ \\
\hline Class $3(n=66)$ & $47.19 \pm 13.50$ & $56.09 \pm 16.85$ & $40.67 \pm 12.34^{\mathrm{d}}$ & $9.22 \pm 5.89$ & $33.91 \pm 3.70$ & $12: 34 \pm 1: 35^{\mathrm{i}}$ \\
\hline Class $4(\mathrm{n}=79)$ & $43.76 \pm 13.69^{b}$ & $60.20 \pm 14.71$ & $42.25 \pm 13.21^{\mathrm{d}}$ & $9.03 \pm 6.03$ & $35.04 \pm 4.93$ & $12: 25 \pm 1: 24^{i}$ \\
\hline Class $5(n=67)$ & $47.16 \pm 6.18$ & $60.15 \pm 12.51$ & $58.94 \pm 4.07$ & $11.25 \pm 7.26$ & $33.72 \pm 5.18$ & $11: 10 \pm 0: 59$ \\
\hline Class $6(\mathrm{n}=88)$ & $50.94 \pm 19.20$ & $56.25 \pm 16.95$ & $41.88 \pm 12.64^{\mathrm{d}}$ & $8.98 \pm 7.45$ & $36.61 \pm 4.95^{\mathrm{g}}$ & $12: 32 \pm 1: 21^{\mathrm{i}}$ \\
\hline Class $7(n=83)$ & $41.59 \pm 11.83^{\mathrm{a}}$ & $53.27 \pm 15.24$ & $38.99 \pm 14.13^{\mathrm{d}}$ & $8.16 \pm 7.09$ & $37.05 \pm 5.87^{\mathrm{g}}$ & $12: 29 \pm 1: 16^{\mathrm{i}}$ \\
\hline Class $8(n=84)$ & $44.52 \pm 10.17^{b}$ & $55.95 \pm 13.53$ & $40.26 \pm 12.18^{d}$ & $9.04 \pm 6.74$ & $33.94 \pm 4.67$ & $11: 51 \pm 1: 46^{\mathrm{h}}$ \\
\hline Class $9(\mathrm{n}=79)$ & $48.34 \pm 4.43$ & $59.48 \pm 13.73$ & $55.68 \pm 9.29$ & $9.84 \pm 5.91$ & $32.55 \pm 3.87$ & $11: 02 \pm 1: 01$ \\
\hline Class $10(n=89)$ & $47.56 \pm 12.98$ & $54.98 \pm 14.27$ & $49.06 \pm 11.43^{\mathrm{e}}$ & $8.69 \pm 6.54$ & $35.91 \pm 5.45^{\mathrm{h}}$ & $12: 15 \pm 1: 17^{\mathrm{i}}$ \\
\hline Class $11(\mathrm{n}=88)$ & $45.06 \pm 13.67$ & $47.97 \pm 13.59^{c}$ & $43.27 \pm 13.51^{\mathrm{d}}$ & $8.34 \pm 6.74$ & $36.98 \pm 5.77^{\mathrm{g}}$ & $12: 53 \pm 1: 54^{j}$ \\
\hline
\end{tabular}

a Significantly fewer than Classes 2, 6, and 9.

b Significantly fewer than Class 6.

c Significantly fewer than Classes 3, 4, 5, 6, 8 and 9.

d Significantly fewer than Classes 1, 2, 5, 9, and 10.

e Significantly fewer than Classes 1, 5, and 9.
${ }^{\mathrm{f}}$ Significantly fewer than Class 5.

g Significantly slower than Classes 2, 3, 5, 8, and 9.

${ }^{\text {h }}$ Significantly slower than Class 9.

${ }^{\text {i }}$ Significantly slower than Classes 5 and 9.

${ }^{\mathrm{j}}$ Significantly slower than Classes 1, 2, 5, 8, and 9. 
Table 3: Percentile rankings for push-ups based on 11 recruit classes from one LEA.

\begin{tabular}{cccc}
\hline Percentile Rank & Push-up Repetitions & Males $(\mathrm{n}=761)$ & Females (147) \\
\hline $90-100$ & $59 \leq$ & 90 & 10 \\
$80-89$ & $51-58$ & 86 & 3 \\
$40-79$ & 50 & 342 & 20 \\
$30-39$ & $43-49$ & 84 & 12 \\
$20-29$ & $38-42$ & 67 & 14 \\
$10-19$ & $31-37$ & 59 & 32 \\
$0-9$ & $\leq 30$ & 33 & 65 \\
\hline
\end{tabular}

Table 4: Percentile rankings for sit-ups based on 11 recruit classes from one LEA.

\begin{tabular}{cccc}
\hline Percentile Rank & Sit-up Repetitions & Males $(\mathrm{n}=761)$ & Females (147) \\
\hline $90-100$ & $76 \leq$ & 32 & 3 \\
$80-89$ & $70-75$ & 130 & 21 \\
$70-79$ & $65-69$ & 72 & 10 \\
$60-69$ & $61-64$ & 61 & 11 \\
$50-59$ & $56-60$ & 78 & 22 \\
$40-49$ & $53-55$ & 72 & 14 \\
$30-39$ & $48-52$ & 93 & 17 \\
$20-29$ & $42-47$ & 68 & 19 \\
$10-19$ & $37-41$ & 78 & 13 \\
$0-9$ & $\leq 36$ & 77 & 17 \\
\hline
\end{tabular}


Table 5: Percentile rankings for mountain climbers based on 11 recruit classes from one LEA.

\begin{tabular}{cccc}
\hline Percentile Rank & Sit-up Repetitions & Males $(\mathrm{n}=761)$ & Females (147) \\
\hline $64-100$ & $61 \leq$ & 54 & 7 \\
$60-64$ & $56-60$ & 246 & 52 \\
$50-59$ & $51-55$ & 57 & 8 \\
$40-49$ & $45-50$ & 96 & 17 \\
$30-39$ & $40-44$ & 91 & 11 \\
$20-29$ & $35-39$ & 72 & 13 \\
$10-19$ & $30-34$ & 71 & 20 \\
$0-9$ & $\leq 29$ & 74 & 18 \\
\hline
\end{tabular}

Table 6: Percentile rankings for pull-ups based on 11 recruit classes from one LEA.

\begin{tabular}{cccc}
\hline Percentile Rank & Pull-up Repetitions & Males $(\mathrm{n}=761)$ & Females (147) \\
\hline $90-100$ & $21 \leq$ & 11 & 0 \\
$80-89$ & $16-20$ & 160 & 3 \\
$70-79$ & $13-15$ & 95 & 1 \\
$60-69$ & $11-12$ & 79 & 2 \\
$50-59$ & 10 & 75 & 3 \\
$40-49$ & $8-9$ & 74 & 1 \\
$30-39$ & $6-7$ & 88 & 6 \\
$20-29$ & $3-5$ & 115 & 12 \\
$13-19$ & $1-2$ & 40 & 28 \\
$0-12$ & 0 & 24 & 91 \\
\hline
\end{tabular}


Table 7: Percentile rankings for 201-m run based on 11 recruit classes from one LEA.

\begin{tabular}{cccc}
\hline Percentile Rank & 201-m Run Time (s) & Males $(\mathrm{n}=761)$ & Females (147) \\
\hline $90-100$ & $\leq 30$ & 161 & 4 \\
$80-89$ & 31 & 62 & 2 \\
$70-79$ & 32 & 79 & 4 \\
$60-69$ & 33 & 66 & 1 \\
$50-59$ & 34 & 75 & 5 \\
$40-49$ & $35-36$ & 143 & 11 \\
$30-39$ & 37 & 44 & 14 \\
$20-29$ & $38-39$ & 61 & 24 \\
$10-19$ & $40-42$ & 39 & 40 \\
$0-9$ & $43 \leq$ & 31 & 42 \\
\hline
\end{tabular}

Table 8: Percentile rankings for 2.4-km run based on 11 recruit classes from one LEA.

\begin{tabular}{cccc}
\hline Percentile Rank & $\begin{array}{c}\text { 201-m Run Time } \\
(\text { min: })\end{array}$ & Males $(\mathrm{n}=761)$ & Females (147) \\
\hline $90-100$ & $7: 50-10: 19$ & 97 & 1 \\
$80-89$ & $10: 20-10: 55$ & 83 & 5 \\
$70-79$ & $10: 56-11: 23$ & 84 & 6 \\
$60-69$ & $11: 24-11: 48$ & 86 & 10 \\
$50-59$ & $11: 49-12: 05$ & 80 & 10 \\
$40-49$ & $12: 05-12: 25$ & 75 & 14 \\
$30-39$ & $12: 26-12: 46$ & 76 & 16 \\
$20-29$ & $12: 47-13: 14$ & 57 & 31 \\
$10-19$ & $13: 15-14: 01$ & 71 & 19 \\
$0-9$ & $14: 02 \leq$ & 52 & 35 \\
\hline
\end{tabular}

